\title{
Linking cavitation erosion in a multi-hole injector with spray and combustion development
}

\author{
Gina M. Magnotti*1, Prithwish Kundu ${ }^{1}$, A. Cody Nunno ${ }^{1}$, Sibendu Som ${ }^{1}$ \\ ${ }^{1}$ Energy Systems Division, Argonne National Laboratory, Lemont, IL, USA \\ *Corresponding author email: gmagnotti@anl.gov
}

\begin{abstract}
It is well known that cavitation erosion in fuel injectors can prevent reliable engine performance after only several thousand hours of operation. However, current simulation tools lack the ability to link flow predictions within the fuel injector to both the efficacy of combustion strategies and lifetime of the injector. Multiphase flow simulation predictions were studied and compared between an informed baseline injector geometry and an x-ray scanned eroded injector geometry. Overall, erosion was found to decrease the fuel mass delivery and injection velocities. A two-stage static coupling approach was employed to link the predicted injection conditions from non-eroded and eroded injectors with the external spray simulations under reacting conditions. Combustion modeling in this coupled approach was carried out using the Unsteady Flamelet Progress Variable approach with a detailed chemical mechanism for $n$ dodecane, comprising of 2,755 species and 11,173 reactions. Erosion in the injectors led to lower rates of spray penetration in comparison to the baseline configurations. Analysis of the reacting spray simulations revealed an insensitivity of ignition to erosion, yet shorter lift off lengths and higher levels of the soot precursor acetylene were predicted in the eroded injector.
\end{abstract}

\section{Keywords}

Cavitation-induced erosion; unsteady flamelet progress variable; coupled injector and spray simulation

\section{Introduction}

To promote mixing and reduce engine-out emissions, direct injection engines have been trending towards increased injection pressures, with many fueling systems in excess of 2000 bar. In spite of the fuel economy and emissions benefits, cavitation-induced damage in fuel injectors can reduce fuel delivery rates and engine performance after only several thousand hours of operation [1]. Because manufacturers must certify engine emissions for their full useful lives, the need to minimize injector wear can often preclude running under the most efficient conditions. As a result, there is a need for improved understanding of the tradeoff among injector operating conditions, erosion risk, combustion performance and emissions. Computational fluid dynamics simulations that link injector and spray simulations can offer valuable insight into the relationship between injector performance and spray development. In a comparative study of the Engine Combustion Network (ECN) cavitating (Spray C) and noncavitating (Spray D) injectors [2], an Eulerian mixture modeling approach was used to dynamically couple the internal flow and near-nozzle spray development. The simulation results highlighted the link between near-nozzle spray spreading and injector geometry, with Spray C having a wider spray cone angle than Spray D. Nocivelli et al. [3] explored the impact of internal flow details on spray development and plume collapse for the ECN Spray G injector using a two stage static coupling approach. It was concluded that accurate prediction of the 2-D injection profile was critical for capturing spray evolution under flare flashing conditions. Although dynamic and static coupling approaches exist to link injector and spray dynamics, there are few published studies on spray behavior for eroded injectors. Recent work from Cristofaro et al. [4] highlighted the impact of erosion on the internal flow and spray 
development under non-reacting conditions. Eroded injector simulations predicted reduced mass flow rate and cavitation formation relative to the nominal injector simulations, which resulted in a larger spray angle and shorter liquid length. It was noted that correct modeling of the internal injector flow requires accurate internal geometry information, and the use of $\mathrm{x}$-ray scanned injector geometry was recommended.

To develop accurate models for injector durability, researchers at Argonne National Laboratory carried out a joint experimental and computational study of the impact of erosion on injector performance [5]. Simulations performed using an x-ray scanned multi-hole injector geometry highlight the strong dependence of internal flow and injection profiles on the local geometry details. In this work, the predicted internal flow profiles from a nominal and an eroded multi-hole injector are coupled to spray simulations under reacting conditions. The findings from this work allow for the impact of erosion to be linked to spray structure, ignition and flame stabilization, and emissions outcomes for the first time.

\section{Computational Model Set-up}

In order to evaluate the impact of erosion on spray and combustion characteristics, multiphase flow simulations were performed in the baseline and eroded A-M3 injectors to extract the injection profiles, as reported in Magnotti et al. [5]. The A-M3 injector is geometrically similar to the Spray Combustion Consortium (SCC) M1 injector from the work of Yasutomi et al. [7]. However, instead of featuring five holes, the A-M3 injector has three side-oriented holes that are nominally oriented at an angle of $73^{\circ}$ with respect to the needle axis and are characterized by a sharp inlet radius of curvature to promote cavitation. The eroded injector surfaces were generated from the x-ray image analysis workflow described in Tekawade et al. [6]. A comparison of the baseline and eroded injectors is shown in Figure 1(a) and (b), respectively, where details from the machining process can be seen in the sac and erosion patterns are evident among the three orifices. Although similar patterns and levels of erosion severity are observed for Orifices 2 and 3, higher levels of erosion are noted in Orifice 1. Based on x-ray imaging and internal flow simulations from Magnotti et al. [5], this difference in erosion behavior is likely due to the groove at the inlet of Orifice 1 that was formed in the machining process, as indicated by the arrow in Figure 1(b). This geometric feature is important to note, as it is believed to induce noticeable differences in the internal flow development and ultimately injection profile from Orifice 1 in both the baseline and eroded injectors.

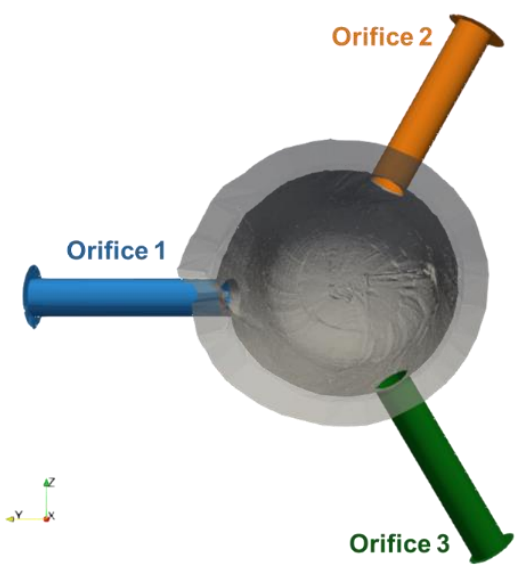

(a)

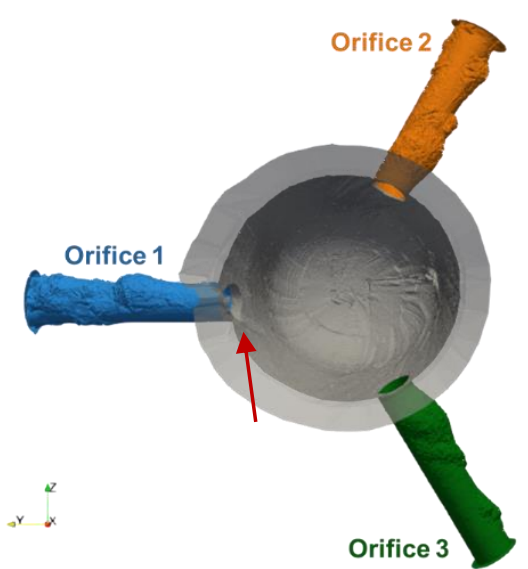

(b)

Figure 1. The (a) baseline and (b) eroded injector tips are compared. Details from the machining process are visible in the sac (grey), while the erosion patterns among the three orifices can be seen in (b). The groove at the inlet of Orifice 1, as indicated by the red arrow, is believed to induce the unique injection behavior from this orifice. 
Using CONVERGE [8], internal flow simulations were performed in the baseline and eroded A-M3 injectors, as shown in Figure 2(a). Details of the modeling approach are not included in this manuscript for the sake of brevity, but the salient details from Magnotti et al. [5] are reproduced here. Liquid $\mathrm{n}$-dodecane at a temperature of $323 \mathrm{~K}$ is injected at a pressure of 500 bar into a nitrogen-filled chamber. Dissolved gas in the fuel is represented using a trace amount of non-condensable gas species $\left(Y_{N 2}=2 \mathrm{e}-05\right)$ in the fuel, based on recommendations from Battistoni et al. [9]. The transient injection event was captured with a moving boundary condition for the needle based on the measured needle lift profile shown in Figure 2(a). The predicted spatio-temporal maps of total void fraction, velocity, turbulence, and temperature were then extracted from the orifice exits to initialize the parcels for the Lagrangian spray simulations. A representative map is shown in Figure 2(b) for Orifice 2 from the eroded injector at approximately $250 \mu \mathrm{s}$ after the start of injection (ASOI) when the needle has reached maximum needle lift. The static coupling approach and parcel initialization strategy used in this work follows the recommendations from Nocivelli et al. [3] and Mondal et al. [10].

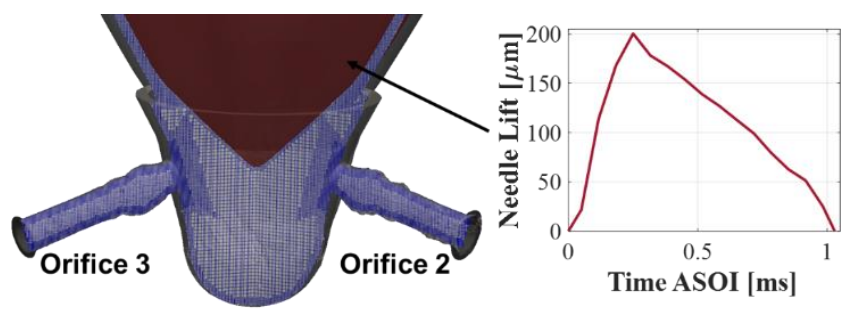

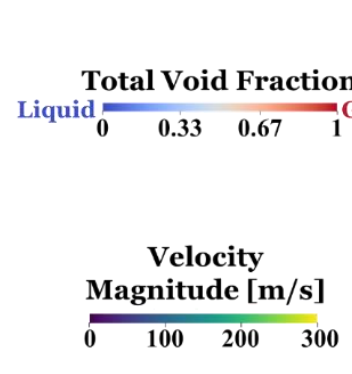

(b)

(a)

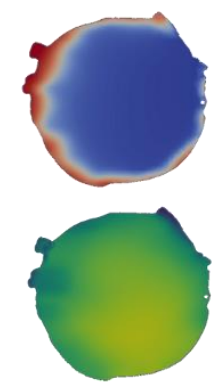

Figure 2. (a) Transient internal flow simulations were performed to extract spatio-temporal injection maps from each of the three orifices, as shown in (b). These maps were used to initialize parcels in a Lagrangian-Eulerian framework, where the computational domain and meshing strategy is shown in (c).

The Lagrangian-Eulerian framework was used to model the spray development from the multihole A-M3 injectors. The computational domain and grid refinement strategy is shown in Figure 2(c). Using a base grid size of $2 \mathrm{~mm}$, fixed embedding and adaptive mesh refinement based on local gradients in temperature, velocity, and fuel mass fraction was employed to achieve a minimum cell size of $250 \mu \mathrm{m}$ and a peak cell count of 2.3 million. The injection maps from the internal flow simulations were used to initialize the parcels. Primary and secondary breakup was represented using the Kelvin-Helmholtz Rayleigh-Taylor model [11], while evaporation was accounted for using the Frossling correlation [12]. Turbulence was modeled using the RNG k- $\varepsilon$ model [13]. To capture autoignition and combustion for a turbulent nonpremixed flame, an Unsteady Flamelet Progress Variable (UFPV) approach [14] was employed. The transient flame evolution is characterized by mixture fraction and its variance, reaction progress variable, and scalar dissipation rate, $X$, and the flame structure is obtained by solving the unsteady flamelet equations. To model the chemical kinetics, solutions were 
tabulated using a detailed chemical mechanism for n-dodecane, which is comprised of 2,755 species and 11,117 reactions and capable of capturing both high and low temperature chemistry combustion regimes [15].

\section{Results and Discussion}

The internal flow simulation predictions of the baseline and eroded A-M3 injectors from Magnotti et al. [5] are used to initialize the parcels in the spray simulations performed in this work. A summary of the injection maps, extracted at each of the orifices exits from the baseline and eroded A-M3 injectors, is provided in Table 1. The effective diameter, $d$, of each orifice is related to its geometric diameter, $d_{0}$, and its area contraction coefficient, $C_{a}$, through Eqn. (1):

$$
d=\sqrt{C_{a}} d_{0}
$$

In the baseline injector, the orifices have similar effective diameters with a spread of $5.80 \mu \mathrm{m}$. In the eroded injector, all of the effective diameters are observed to increase by up to $11 \%$. Due to pressure losses associated with the local area changes, the fuel mass flow rate decreases in Orifices 2 and 3 while a slight increase is observed in Orifice 1 . This divergent behavior is due to the erosion patterns in the orifice that induce a high velocity jet along the bottom of the orifice, and results in a higher injection velocity and narrower spray cone angle than is seen in Orifices 2 and 3.

Table 1 - The predicted injection profiles from the orifices in the baseline and eroded injectors are summarized. Although erosion in Orifices 2 and 3 leads to wider sprays with lower injection velocities, the unique geometry in Orifice 1 lead to a narrower spray with a relatively higher injection velocity.

\begin{tabular}{c|l|llll}
\hline Injector & Orifice & $\begin{array}{l}\text { Effective } \\
\text { Diameter }[\mu \mathrm{m}]\end{array}$ & $\begin{array}{l}\text { Fuel Mass } \\
\text { Flow Rate }[\mathrm{g} / \mathrm{s}]\end{array}$ & $\begin{array}{l}\text { Average Injection } \\
\text { Velocity }[\mathrm{m} / \mathrm{s}]\end{array}$ & $\begin{array}{l}\text { Steady Spray } \\
\text { Cone Angle }\left[^{\circ}\right]\end{array}$ \\
\hline Baseline & 1 & 160.1 & 4.72 & 322 & 18.7 \\
& 2 & 163.7 & 4.79 & 312 & 19.1 \\
& 3 & 165.9 & 4.70 & 299 & 19.8 \\
\hline Eroded & 1 & 172.5 & 4.74 & 279 & 19.5 \\
& 2 & 182.3 & 4.72 & 249 & 25.6 \\
& 3 & 178.0 & 4.64 & 256 & 23.5
\end{tabular}

These differences in the injection profiles among the orifices and between the injectors results in noticeable differences in the spray development. In order to define and track the spray boundary, the optical thickness is calculated in a manner that is consistent with laser extinction and diffused back illumination. As outlined in [16], the Mie solution to Maxwell's equation can be used to relate CFD-predicted spray quantities with the attenuation of light as it interacts with a droplet field. Ultimately, the optical thickness, $\tau$, can be defined as

$$
\tau=\frac{z}{V} \sum_{j} C_{\text {ext }, j} N_{j}
$$

where $z$ is the illumination path-length through $N_{j}$ number of droplets $j$ within the probed volume $V$. $C_{\text {ext,jis }}$ is the corresponding extinction cross-section for an n-dodecane droplet of size $d_{j}$ in air, which is calculated from MiePlot [17] based on the incident wavelength of light (633 nm) and collection angle of the optics (220 mrad). The relationship defined in Equation (2) can be used to relate droplet parameters to attenuation of light at locations in the spray where scattering of light is dominated by single and independent scattering events. 


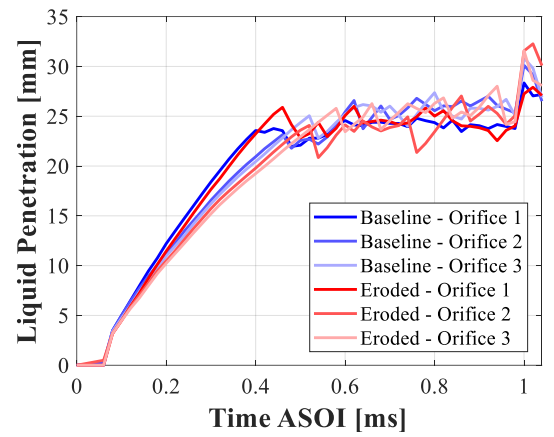

(a)

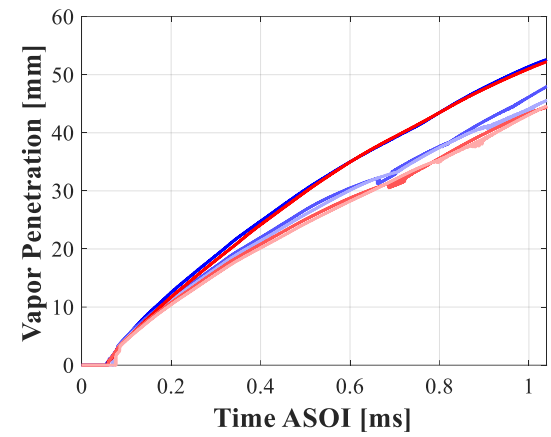

(b)

Figure 3. The (a) liquid and (b) vapor penetration for the spray plumes issued from the baseline and eroded A-M3 injector are compared.

By defining the spray boundary using an iso-contour for $\tau$ equal to unity, liquid penetration can be quantified in time. A comparison of liquid penetration among the orifices from the baseline and eroded A-M3 injectors is shown in Figure 3(a). During the transient spray development period from $60 \mu$ s to $0.6 \mathrm{~ms}$, spray penetration rates are seen to be lower for Orifices 2 and 3 relative to Orifice 1 for both the baseline and eroded injectors due to their wider spreading angles. However, the transient liquid penetration is similar among the baseline and eroded Orifice 2 and 3 spray plumes, with a slightly slower penetration rate from the eroded orifices. By time averaging the liquid penetration during the steady portion of injection from $0.6 \mathrm{~ms}$ to $0.9 \mathrm{~ms}$, the liquid length can be calculated, as enumerated in Table 2. For Orifices 2 and 3, the eroded injector is observed to have shorter liquid lengths than those from the baseline injector. This trend is consistent with the predictions from Cristofaro et al. [4] for liquid penetration from single hole nominal and deformed injector geometries under non-reacting conditions. In contrast, erosion in Orifice 1 is observed to result in an increased liquid length.

Table 2 - Key spray and combustion parameters are compared among the orifices and between the baseline and eroded A-M3 injector.

\begin{tabular}{c|l|llll}
\hline Injector & Orifice & $\begin{array}{l}\text { Liquid Length } \\
{[\mathrm{mm}]}\end{array}$ & $\begin{array}{l}\text { Flame Lift Off } \\
\text { Length [mm] }\end{array}$ & $\begin{array}{l}1^{\text {st }} \text { Stage Ignition } \\
\text { Delay }[\mathrm{ms}]\end{array}$ & $\begin{array}{l}2^{\text {nd }} \text { Stage Ignition } \\
\text { Delay [ms] }\end{array}$ \\
\hline Baseline & 1 & 24.2 & 6.5 & 0.18 & 0.30 \\
& 2 & 25.7 & 7.1 & 0.18 & 0.30 \\
& 3 & 25.6 & 7.1 & 0.18 & 0.30 \\
\hline Eroded & 1 & 24.7 & 5.1 & 0.16 & 0.32 \\
& 2 & 24.1 & 6.1 & 0.16 & 0.32 \\
& 3 & 25.3 & 6.2 & 0.16 & 0.32
\end{tabular}

The spreading of sprays and level of entrainment can be compared among the orifices by evaluating the vapor penetration, as shown in Figure 3(b). For each spray plume, vapor penetration is tracked according to the Engine Combustion Network (ECN) standard [18], which defines the vapor boundary as the maximum distance between the orifice exit and the location where the mixture fraction is $0.1 \%$. A reduction in vapor penetration up $6.6 \%$ is noted for eroded Orifices 2 and 3 relative to those from the baseline injector. Although a similar trend in decreased vapor penetration is also observed in the eroded Orifice 1, the difference is less pronounced with a decrease of less than $1 \%$ from the baseline.

In order to compare the combustion characteristics among the orifices, the time evolution of the flame from ignition to stabilization is analyzed, as shown in Figure 4(a) and (b) for the 
baseline and eroded A-M3 injector. For each spray plume at each instant in time, the stoichiometric mixture fraction, $Z_{s t}$, equal to 0.045 for this condition, is shown as a white isocontour. Narrower plumes are consistently observed for Orifice 1 across all time instants relative to Orifice 2 and 3 , which is consistent with the narrow spray cone angle (c.f. Table 1) and longer vapor penetration noted in Figure $3(\mathrm{~b})$. Formaldehyde $\left(\mathrm{CH}_{2} \mathrm{O}\right)$ formation is visualized to identify the cool flame and onset of first stage ignition, while the ground-state hydroxyl radical $(\mathrm{OH})$ is visualized to identify the high temperature combustion region and second stage ignition. A red iso-line with a radius of $7.0 \mathrm{~mm}$ is also overlaid as a basis of comparison for the flame lift off length. In accordance with the ECN modeling recommendations [18], the flame lift off length is defined using an iso-contour of ground-state $\mathrm{OH}$ mass fraction equal to $2 \%$ of the maximum in the domain ( $\left.\mathrm{Y}_{\mathrm{OH}, \mathrm{ref}} \sim 1 \mathrm{e}-05\right)$, while the ignition delay is defined as the first time instant when $\mathrm{OH}$ mass fraction reaches $Y_{O H}$,ref. A comparison of the ignition delays and flame lift off lengths is tabulated in Table 2.

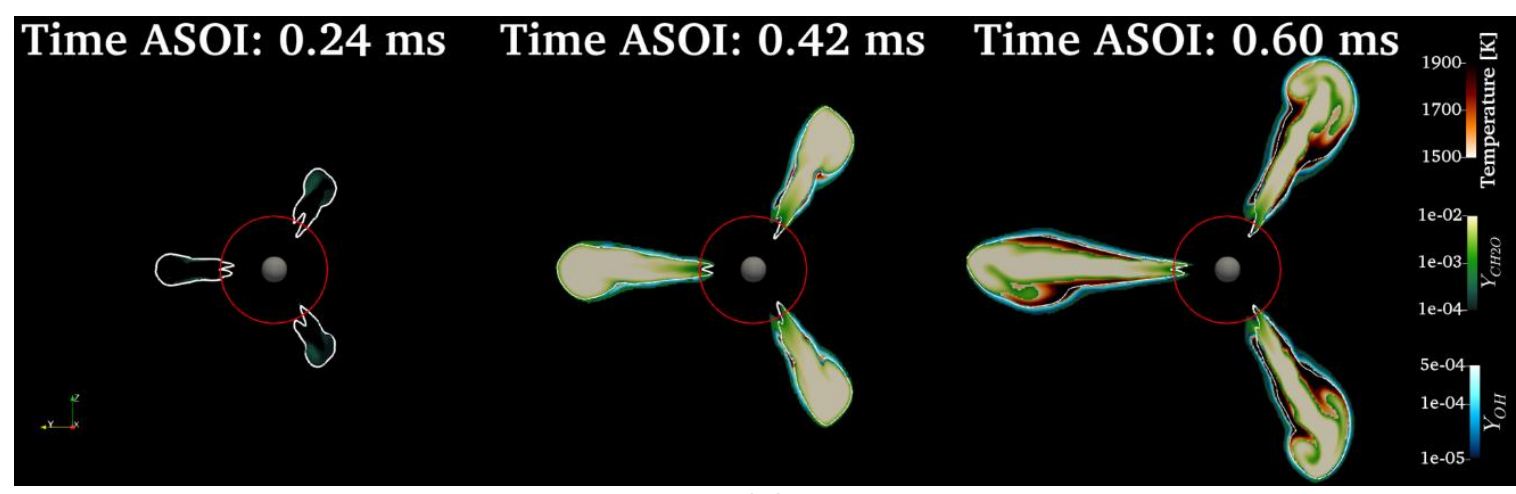

(a)

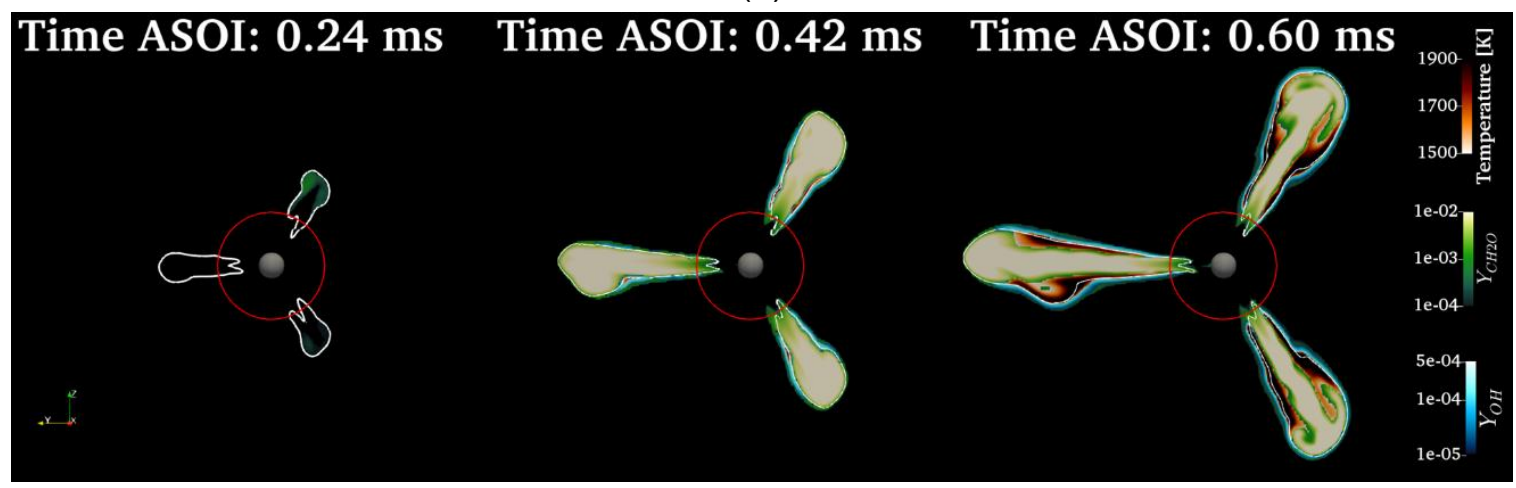

(b)

Figure 4. Time evolution of the flame from ignition to quasi-stable flame is compared between the (a) baseline and (b) eroded A-M3 injector. The flame is visualized in terms of $\mathrm{CH} 2 \mathrm{O}, \mathrm{OH}$, and temperature. An iso-line for the stoichiometric mixture fraction is overlaid in white at each time instant. A reference flame lift off length of $7.0 \mathrm{~mm}$ is shown in red for basis of comparison.

For the baseline injector shown in Figure 4(a), similar first and second stage ignition delays were predicted across all orifices. Similar flame lift off lengths were also predicted, although a slightly shorter lift off length from Orifice 1 was indicated. Comparison with the flame evolution from the eroded injector in Figure 4(b) reveals minimal effect of erosion on the predicted ignition delays. In general, erosion is observed to have minimal effect on first and second stage ignition, with only a slight decrease in first stage ignition delay to $0.16 \mathrm{~ms} \mathrm{ASOI}$ and increase in second stage ignition delay to $0.32 \mathrm{~ms}$ ASOI. The insensitivity of ignition delay to changes in the injection profiles across the baseline and eroded orifices is consistent with the findings from Maes et al. in their comparison of the single-hole ECN cavitating (Spray C) and 
non-cavitating (Spray D) injectors, which have similarly sized orifice diameters (179-191 $\mu \mathrm{m})$ operated under a similar condition $\left(22.8 \mathrm{~kg} / \mathrm{m}^{3}, 900 \mathrm{~K}, 15 \% \mathrm{O}_{2}\right)$ to that studied in this work [19]. However, erosion was observed to influence flame lift off length. For all orifices, the wider spreading angles in the eroded injector led to shorter lift off lengths. Although this finding is qualitatively consistent with those from Maes et al. in comparing the lift off lengths of the Spray $C$ and D injectors [19], the predicted lift off lengths in the eroded A-M3 injector do not directly correlate with the spreading angle. The shorter lift off length for Orifice 1 is likely due to the enhanced mixing field from the narrower spreading angle and higher injection velocities relative to Orifices 2 and 3, as noted in Table 1. This mixing field ultimately results in a shorter flame lift off length. To investigate the physics controlling the differences in flame structure among the orifices, simulations will be performed coupling UFPV in a Large Eddy Simulation to allow for more accurate predictions of turbulent mixing and turbulence-chemistry interaction. The shorter lift off lengths in the eroded injector inversely correlated with increased levels of acetylene $\left(\mathrm{C}_{2} \mathrm{H}_{2}\right)$, suggesting a higher sooting tendency of the eroded injector at the condition studied.

\section{Conclusions}

This work presents a computational exploration of the impact of erosion on the spray and combustion development from a multi-hole injector. Internal flow simulations from a baseline and an x-ray scanned eroded A-M3 three-hole injector were used to define the injection conditions for reacting spray simulations. Evaluation of the $\mathrm{x}$-ray scanned sac geometry highlighted a groove at the inlet of Orifice 1 from the manufacturing process that caused different spray and combustion behavior of this orifice relative to Orifices 2 and 3. Comparison of the injection profiles, spray development, and combustion characteristics among the orifices and between the injectors revealed the following findings:

- In comparison to the baseline injector, lower fuel mass delivery rates were predicted in eroded Orifices 2 and 3 . In contrast, a higher fuel mass delivery rate was predicted in eroded Orifice 1 due to the formation of a high velocity jet along the bottom of the orifice surface. The high velocity jet also resulted in a narrower spreading angle relative to Orifices 2 and 3 .

- Across injectors, faster spray penetration was predicted from Orifice 1 relative to Orifices 2 and 3 due to the wider spreading angle. Although erosion did not affect spray penetration in Orifice 1, slower vapor penetration was predicted from Orifices 2 and 3.

- A two-stage ignition process was predicted. Similar first and second stage ignition delays were predicted across all orifices. However, erosion was observed to shorten the flame lift off length. Although the wider spreading angle predictions in the eroded injector helps to partly explain this trend, differences in mixture formation from increased fuel mass delivery were found to induce a shorter lift off length for Orifice 1 relative to Orifice 2 and 3 . The shorter lift off lengths in the eroded injector inversely correlated with increased levels of acetylene, suggesting a higher sooting tendency of the eroded injector at the condition studied.

\section{Acknowledgments}

The submitted manuscript has been created by UChicago Argonne, LLC, Operator of Argonne National Laboratory (Argonne). Argonne, a U.S. Department of Energy Office (DOE) of Science laboratory, is operated under Contract No. DE-AC02-06CH11357. The U.S. Government retains for itself, and others acting on its behalf, a paid-up nonexclusive, irrevocable worldwide license in said article to reproduce, prepare derivative works, distribute 
copies to the public, and perform publicly and display publicly, by or on behalf of the Government.

Argonne National Laboratory's work was supported by the U.S Department of Energy under contract DE-AC02-06CH11357. The authors gratefully acknowledge the computing resources provided on Bebop, a high-performance computing cluster operated by the Laboratory Computing Resource Center at Argonne National Laboratory, and Convergent Science Inc., for providing the CONVERGE CFD software licenses.

\section{References}

1. Tzanetakis, T. et al., SAE Int. J. Adv. \& Curr. Prac. in Mobility, 1(2):654-674, 2019.

2. Westlye, F., Battistoni, M., Skeen, S., Manin, J. et al., SAE Technical Paper 2016-010860, 2016.

3. Nocivelli, L. et al., "Effect of Ambient Pressure on the Behavior of Single-Component Fuels in a Gasoline Multi-Hole Injector," in ASME 2019 Internal Combustion Engine Division Fall Technical Conference, ICEF 2019, 2019.

4. Cristofaro, M. et al., "A numerical study on the effect of cavitation erosion in a diesel injector," Applied Mathematical Modelling, vol 78: pp. 200-216, 2020.

5. Magnotti, G.M. et al., "Impact of Injector Geometry Details on Cavitation and Erosion Development in a Multi-hole Aluminum Injector Nozzle," Proceedings of the $11^{\text {th }}$ International Symposium on Cavitation, Daejon, Korea, May 10-13, 2021.

6. Tekawade, A. et al., "High-fidelity geometry generation from CT data using convolutional neural networks," Proc. SPIE 11113, Developments in X-Ray Tomography XII, 111131X (10 September 2019).

7. Yasutomi, K., Hwang, J., Pickett, L.M., Sforzo, B., et al., "Transient Internal Nozzle Flow in Transparent Multi-Hole Diesel Injector", SAE Technical Paper 2020-01-0830.

8. Richards, K.J., Senecal, P.K., and Pomraning, E., CONVERGE 3.0 Manual, Convergent Science, Madison, WI (2020).

9. Battistoni, M., Duke, D., Swantek, A., Tilocco, F., et al., "Effects of Noncondensable Gas on Cavitating Nozzles". Atomization and Sprays, 25: p. 453-483, 2015.

10. Mondal, S. et al., "Accelerating the Generation of Static Coupling Injection Maps Using a Data-Driven Emulator," SAE Technical Paper 2021-01-0550, 2021.

11. Beale, J.C. and Reitz, R.D., "Modeling Spray Atomization with the KelvinHelmholtz/Rayleigh-Taylor Hybrid Model". 1999. 9(6): p. 623 - 650.

12. Amsden, A.A., "KIVA-II: A Computer Program for Chemically Reactive Flows with Sprays". 1989.

13. Han, Z. and Reitz, R.D., "Turbulence Modeling of Internal Combustion Engines Using

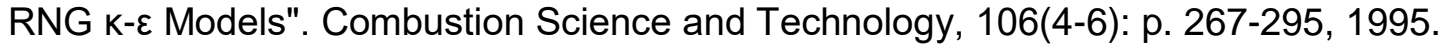

14. Nunno, A.C., Kundu, P., Som, S., "Extending the Unsteady Flamelet-Progress Variable Model to Split Injection and Compression Ignition Engine Applications". (in preparation)

15. Westbrook, C.K., Pitz, W.J. et al., "A comprehensive detailed chemical kinetic reaction mechanism for combustion of n-alkane hydrocarbons from n-octane to n-hexadecane". Combustion and Flame, 156(1): 181-199, 2009.

16. Magnotti, G.M. and Genzale, C.L., Atomization and Sprays, 25(5): p. 397-424, 2015.

17. Laven, P. "MiePlot." http://www.philiplaven.com/mieplot.htm

18. Engine Combustion Network, "Modeling Standards and Recommendations." https://ecn.sandia.gov/diesel-spray-combustion/computational-method/modelingstandards/.

19. Maes, N. et al., "Spray penetration, combustion, and soot formation characteristics of the ECN Spray C and Spray D injectors in multiple combustion facilities." Applied Thermal Engineering, 172: pp. 115136, 2020. 